\title{
Breakfast habit and quality in students from two public primary schools in the city of Santa Fe
}

\author{
Valeria Fugas, B.S. ${ }^{a}$, Eugenia Berta, B.S. ${ }^{a}$, Florencia Walz, M.Sc. ${ }^{b}$, \\ Ma. Alejandra Fortino, M.D. ${ }^{a}$, and Marcela J. Martinelli, M.D. ${ }^{a}$
}

\begin{abstract}
Introduction. Breakfast provides the necessary energy and nutrients to achieve an optimal physical and mental performance.

Objective. To find out breakfast frequency, factors that influence breakfast habit and skipping, breakfast quality and snack intake in children from public schools in the city of Santa Fe.

Population and Methods. Descriptive, crosssectional study. A total of 637 students were assessed using a closed-ended question survey. Results. Seventy five percent of children had breakfast on a daily basis; only $1.6 \%$ had a good quality breakfast. Eating breakfast every day or some days did not depend on having the company of a family member. In the case of first to fifth grade children, the weekly frequency depended on having a family member who made it $(p=0.04)$. The main cause for skipping breakfast was lack of time. Twenty-threepercent of children in sixth and seventh grade indicated feeling unwell when having breakfast. More than $50 \%$ of children watched television while having breakfast.
\end{abstract}

Most students in first to third grade had breakfast that could be improved (41\%) and which was insufficient $(41 \%)$. An insufficient quality breakfast was more common among fourth and fifth grade students (50\%). A remarkable piece of information is the number of sixth and seventh grade children who had a poor quality breakfast $(16 \%)$.

a. Biological science department.

b. Applied mathematics and statistics department.

School of Biochemistry and Biological Science. Universidad Nacional del Litoral, Santa Fe, Argentina.

\section{E-mail Address:}

Marcela Martinelli, M.D.: mmartine@fbcb. unl.edu.ar

\section{Conflict of Interest: None.}

Funding: Universidad Nacional del Litoral. Social Outreach Project. UNL No. 500/11. File No. 571334. allowing individuals to accomplish an optimal mental and physical performance. ${ }^{1-4}$

Several studies have revealed that children who do not have breakfast do not cover the recommended daily intake of vitamins A, E, B6 and folate, and of minerals such as calcium, iron and zinc. ${ }^{5-7}$ Although breakfast is important, skipping it or having a poor or insufficient breakfast is common among children in several countries. $^{\mathrm{S}-11}$

Studies conducted in Spain, which included 5000 children and young subjects aged 2-25 years old, indicated that $5 \%$ to $9 \%$ of them skipped breakfast and only $25 \%$ to $29 \%$ had an adequate breakfast. ${ }^{12}$

One study conducted in students aged 7-12 years in Greater Buenos Aires revealed that $94 \%$ of them did have breakfast, but only $5 \%$ had a nutritionally complete breakfast. ${ }^{13}$ Among the varied reasons for skipping this meal, the most important ones were: "I don't feel like it," "it makes me feel unwell," "I'm tired," "I have no time," "I have to make it myself," and "I have to eat breakfast alone." 13,14

A nutritionally complete and balanced quality breakfast includes at least one serving of three food groups: dairy, cereals and fruits. ${ }^{1,15-17}$

The Food Guidelines for the Argentinean Population highlight the relevance of starting the day with a good breakfast upon waking up and supplementing it with a mid-morning snack. The main role of these snacks should be that of complementing breakfast quality. ${ }^{16}$

This study was promoted by the lack of sufficient national and local data regarding breakfast intake among 
school-aged children, and its main objectives included:

- To be aware of breakfast intake weekly frequency and factors associated with the habit of having breakfast among students from two public schools in the city of Santa Fe.

- To establish breakfast quality and the final quality following a snack.

\section{POPULATION AND METHODS}

This study was conducted between April and May, 2012, in two of the four public primary schools located in downtown Santa Fe, taking into consideration that: none of them received food assistance, both had a candy stand, students from both schools had a comparable socioeconomic level, and both had similar enrollment rates. Schools were selected by the School Cooperative Federation depending on the willingness of the headmasters to conduct the research.

The total enrollment of both schools was 817 students in the morning classes. This was a crosssectional, descriptive study with children from first to seventh grade who voluntarily agreed to participate and whose parents gave their written informed consent. Children indicating to have modified their food intake patterns as a result of a pre-existing disease were excluded from the analysis.

Thus, the resulting sample was made up of 637 male and female students.

The survey used in this study was based on that by Angeleri, et al. The document was modified using closed-ended question options in relation to the reasons for skipping breakfast and questions were added to define factors associated with breakfast frequency which were of interest for this study. In addition, the variety and the serving of each food type eaten at breakfast were considered, and children who did not have breakfast were excluded from the poor quality category, as defined by the author.

Surveys were administered individually by ten trained survey takers (B.S. in Nutrition and thesis students).

A pilot test was performed to validate the surveys and predict any inconvenience with their administration.

The following outcome measures were assessed: breakfast weekly frequency (categories: every day, sometimes, never), factors associated with breakfast frequency: having company (categories: alone or with a family member) and preparation (categories: on their own or by a family member); activities done during breakfast (categories: watching television, doing homework, other); causes for skipping breakfast (categories: lack of time, no hunger, feeling unwell); breakfast quality and final quality considering the mid-morning snack.

The outcome measure breakfast quality was analyzed as per the enKid study criteria, used in several other investigations, ${ }^{1,13,17}$ which establish having one serving of each of the following food groups: dairy, cereals and fruits. These criteria are consistent with those established in the Food Guidelines for the Argentinean Population. ${ }^{16}$ For "serving," we considered the definition indicated in Chapter V of the Argentine Food Code. ${ }^{18}$ In order to assess the serving size, home measuring elements were used (cups, glasses, spoons), and products which are usually fractioned, such as number of crackers or cookies, bread loaves and pots of yogurt).

The categories of the outcome measure breakfast quality were:

- Good quality: it includes at least one serving of each of the three food groups required.

- Quality that can be improved: it includes one serving of two different food groups.

- Insufficient quality: it includes one serving of only one food group.

- Poor quality: it includes food other than those in the three required groups (infusions, candies, etc.).

Snacks were taken as an outcome measure supplementary to the breakfast quality outcome considering that quality improves when the necessary food group is included at mid-morning to result in a good quality breakfast.

Results were expressed for all studied students and by education level (first to third grade, fourth and fifth grade, sixth and seventh grade). Data were systematically processed using the SPSS software, v17. Results in the different outcome measure categories were expressed as percent relative frequency. The associations between the breakfast frequency outcome and the included factors were assessed using the $\chi^{2}$ test and odds ratio $(\mathrm{OR})$ values were also estimated.

\section{RESULTS}

Results are for all surveyed students because both schools were taken as homogenous units as per this study's inclusion criteria. The sample was made up of 637 male and female students: 282 students from first to third grade, (average age: $6.9 \pm 0.8$ years old); 188 students from fourth 
and fifth grade (average age: $9.4 \pm 0.5$ years old), and 167 students from sixth and seventh grade (average age: $11.4 \pm 0.5$ years old).

Figure 1 shows breakfast frequency results for all studied children and by education level. Out of all surveyed children, $75 \%$ indicated to have breakfast on a daily basis.

The analysis of factors that may impact breakfast weekly frequency showed that there was no association with the fact of being alone or accompanied by a family member for breakfast in any of the education levels ( $p>0.05$ ).

Among the first to third grade and the fourth and fifth grade students, breakfast weekly frequency depended on having a family member who made it $(p=0.04)$. For each child who had breakfast on a daily basis and made it himself/

FIGURE 1. Weekly frequency of breakfast consumption among students

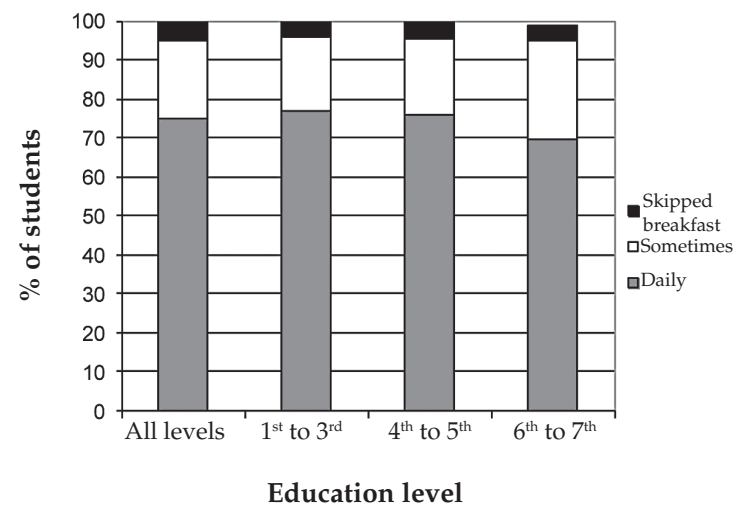

Figure 2. Activities performed by children while having breakfast

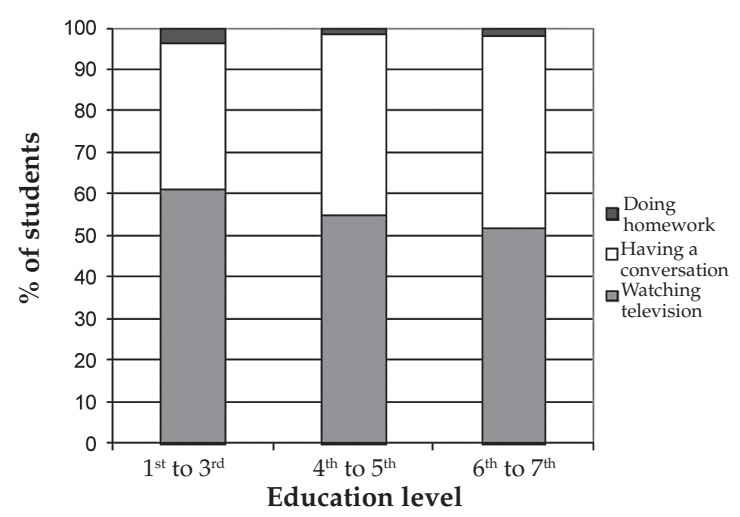

herself, there were three children who had it made by a family member $(\mathrm{OR}=3)$. In the case of older children (sixth and seventh grade), having breakfast daily or sometimes did not depend on having somebody who made it $(\mathrm{p}=0.8)$.

More than half of the children from all education levels indicated that their main activity while having breakfast was watching television (Figure 2).

The main reason for students from all levels to skip breakfast or to have it sometimes was lack of time ( $40 \%$ in the first to fifth grade group and $30 \%$ in the sixth and seventh grade group). In the second place, students from first to third grade and fourth and fifth grade indicated that they were not hungry. Twenty three percent of sixth and seventh grade students stated that they felt unwell at the time of having breakfast; but this frequency was much lower in the other two levels $(7 \%)$.

On the day of the survey, only $1.6 \%$ of children had a good quality breakfast; $33.1 \%$ had breakfast whose quality could be improved; $45.4 \%$, had breakfast of insufficient quality; $8.9 \%$ had a poor quality breakfast, and $11 \%$ did not have any breakfast. When breakfast quality was analyzed by education level, a similar percentage of children in all groups had skipped breakfast (Figure 3). Most students in first to third grade had a type of breakfast whose quality could be improved $(41 \%)$ and breakfast of insufficient quality $(41 \%)$. In the case of fourth and fifth grade children, a reduction was observed in the breakfast whose quality could be improved (30\%), with a shift towards having an insufficient quality breakfast $(50 \%)$. The same trend was observed

FIGURE 3. Breakfast quality as per education level

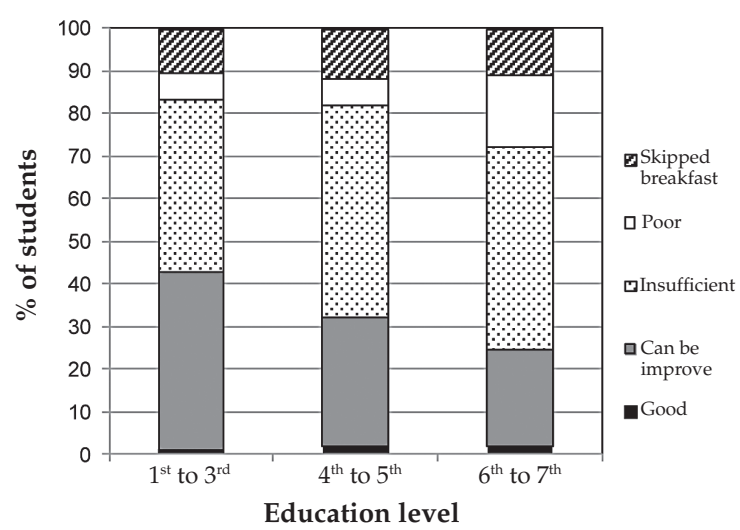


in the sixth and seventh grade group, which also showed an increased number of children having a poor quality breakfast (16\%).

Between $80 \%$ and $90 \%$ of children had a mid-morning snack. After including snack consumption in all education levels, a mild improvement was observed in the proportion of children who supplemented their breakfast to become a good quality breakfast, but it was significant only in the first to third grade group $(p=0.04)$. However, only $6 \%$ of these children achieved a final good quality breakfast (Table 1).

\section{DISCUSSION}

Results show that most children from all grades in both primary schools have breakfast on a daily basis $(75 \%)$, while only $5 \%$ never eat breakfast. This is similar to the findings of a study conducted among Spanish children aged 9-13 years old. ${ }^{19}$ In our study, no variations were observed in breakfast frequency for the different education levels, unlike another research study that showed that older children (aged 11-14 years old) had breakfast less frequently. ${ }^{20}$

Breakfast habit among children may be associated with different factors. It has been demonstrated that breakfast frequency improves when breakfast is eaten in the company of another person. ${ }^{21}$ However, this study found no dependence between such outcome measure and the fact of being alone or companied by a family member in any education level. A comparable situation was observed in other studies where most children have breakfast alone. ${ }^{6,19}$

In relation to making breakfast, our study found that children from first to fifth grade most commonly have breakfast when a family member makes it for them. It is very important to have a family member taking care of making breakfast. Parents or legal guardians are responsible for providing children with the adequate food for breakfast. ${ }^{22,23}$

In contrast to this, the fact of having breakfast daily or sometimes among older children does not depend on having a family member making it, so they are responsible of choosing the food they have at breakfast.

At the time of having breakfast, more than $50 \%$ of children of all ages watch television, and this is similar to what has been observed among Spanish students, where $40 \%$ said they watched television during breakfast. ${ }^{24}$ This may be a distraction while eating and may take time away from breakfast time. In addition, to a large extent, TV commercials determine children's preference for certain food, which in general are not healthy. ${ }^{25}$

Among the reasons for skipping breakfast or for having breakfast sometimes, the main one in all ages is the lack of time. Secondly, children from first to fifth grade stated that they were not hungry. Similar results were obtained in other studies, where the main reasons for skipping breakfast were lack of time and not feeling hungry early in the morning. ${ }^{13,14}$ Lack of time may be related to the time children go to bed, the time classes start and getting up late. Some authors have shown that the time devoted to breakfast is related to the quantity of food consumed, thus conditioning breakfast quality. ${ }^{21}$

Another factor was pointed out by sixth and seventh grade students: feeling unwell when they have breakfast before going to school.

In relation to breakfast quality, out of all surveyed children, only $1.6 \%$ had a good quality breakfast, and half of all children had an insufficient quality breakfast. Similar values were observed in the different education levels for this outcome measure. A study conducted among children in Greater Buenos Aires analyzed the quality of breakfast only from a qualitative perspective. This study showed that only 5\% of children had a good quality breakfast. ${ }^{13}$ Two studies carried out in Spain among 9-13 year old children found that $8-10 \%$ of children had dairy, cereals and fruits. ${ }^{26,19}$

The results of another study conducted in Spain among immigrant children (average age: 11 years old) varied greatly depending on their country of origin, and for this reason a good quality breakfast ranged between $11.5 \%$ and $51.5 \% .{ }^{21}$ Having a good quality breakfast varies to a large extent depending on the population of studied children. It should be noted that most surveyed children in this study have breakfast

TABLE 1. Students who have a good quality breakfast before and after including a snack

1 st to 3 rd grade 4 th and 5 th grade 6 th and 7 th grade

\begin{tabular}{lccc}
$\begin{array}{l}\text { Good quality } \\
\text { breakfast }\end{array}$ & $\mathrm{n}=282$ & $\mathrm{n}=188$ & $\mathrm{n}=167$ \\
$\begin{array}{l}\text { At first time of } \\
\text { the day }\end{array}$ & $1.1 \%$ & $2 \%$ & $1.1 \%$ \\
After the snack & $6 \%^{*}$ & $4.5 \%$ & $1.7 \%$ \\
\hline
\end{tabular}

${ }^{*} p \leq 0,05$ 
alone and are probably responsible for choosing the food they eat, and this may determine breakfast quality. ${ }^{24}$

When analyzing breakfast quality in terms of grades, it can be seen that most first to third grade students usually have a type of breakfast that can be improved or that is insufficient. Those in fourth and fifth grade have a higher rate of insufficient quality breakfast. And this is also observed for sixth and seventh grade students, but this group has a larger number of children who eat a poor quality breakfast. This is consistent with previous studies that indicate that as children grow older, they tend to eat a lighter breakfast. ${ }^{27}$ Reverse correlations have been observed between age and type of food eaten at breakfast; i.e., older students include less varied food in their breakfast. ${ }^{6}$ Another study detected a higher number of children aged 12-13 years old $(16 \%)$ who had a good quality breakfast. ${ }^{1}$ In spite of the variations presented by the different studies, it has been observed that very few children have a good quality breakfast.

From $80 \%$ to $90 \%$ of children have a midmorning snack. However, most surveyed children from both schools were not able to supplement their breakfast quality with snacks. Such situation may probably be related to the fact that children are unaware of the types of food they should eat at breakfast and as a snack. Besides, children usually have their own pocket money and possibly receive no guidance from adults regarding which food to choose. In addition, candy stands located inside schools offer a wide variety of appetizing but unhealthy products. Fernández San Juan, et al. observed that children who skip breakfast before going to school usually receive money to buy snacks, which tend to be of low nutritional quality. ${ }^{28}$ It is worth noting that, in this study, breakfast quality was assessed considering the amount of food consumed, a factor not included in other studies. This allowed us to assess breakfast as per the recommendations made in the Food Guidelines for the Argentinean Population. A natural limitation of this type of work is that the information was reported by participants, so it is not possible to "warrant" that children were totally sincere and accurate when answering.

Based on the results of this study it is not possible to draw any conclusions regarding the primary school population because the sample is only representative of schools bearing similar features to those considered in this study. In spite of this limitation, it is valid to recommend that actions be taken in relation to food and nutrition education for primary school students with the aim of developing in them the habit of having a good quality breakfast at an early stage and which will last throughout their lives. On the other hand, these actions should also include students' families, since they are one of the most important determining factors as far as food preferences among child population.

\section{CONCLUSIONS}

Seventy five percent of children have breakfast on a daily basis; only $1.6 \%$ have a good quality breakfast. Fifty percent of children have only one serving of the recommended food groups early in the morning and then a snack which is not enough to supplement the final quality of breakfast.

Factors associated with skipping breakfast are lack of time (36\%), not feeling hungry (21\%), feeling unwell at the time of breakfast $(23 \%)$ among sixth and seventh grade students.

Among the first to fifth grade students, the weekly frequency of breakfast depends on having a family member who makes it $(p=0.04)$.

\section{Acknowledgments}

To Juan Villafañe, chair of the School Cooperative Federation of the La Capital Department, Santa Fe, for his concern and actions regarding child nutrition. To the headmasters, teachers and students who enthusiastically participated in this project.

\section{REFERENCES}

1. Herrero Lozano R, Fillat Ballesteros JC. Estudio sobre el desayuno y el rendimiento escolar en un grupo de adolescentes. Nutr Hosp 2006;21(3):34652.

2 JofréJM,Arenas MC,AzpirozR, DeBertoliMA.Importancia del desayuno en el estado nutricional y el procesamiento de la información en escolares. Universidad de Psicología de Bogotá 2007;6(2):371-82.

3. Pivik RT, Tennal KB, Chapman SD, Gu Y. Eating breakfast enhances the efficiency of neural networks engaged during mental arithmetic in school-aged children. Physiology $\mathcal{E}$ Behaviour 2012;106:548-55.

4. Wesnes K, Pincock C, Scholey A. Breakfast is associated with enhanced cognitive function in schoolchildren. An internet based study. Appetite 2012;59:646-9.

5. Nicklas TA, Bao W, Webber LS, Berenson GS. Breakfast consumption affects adequacy of total daily intake in children. J Am Diet Assoc 1993;93(8):886-91.

6. Ortega RM, González-Rodríguez LG, Jiménez Ortega AI, Perea Sánchez JM, et al. The importance of breakfast in meeting daily recommended calcium intake in a group of schoolchildren. Am J Coll Nutr 1998;17:19-24.

7. Sampson AE, Dixit S, Meyers AF, Houser R. The nutritional 
impact of breakfast consumption on the diets of inner-city African-American elementary school children. J Nat Med Assoc 1995;87(3):195-202.

8. Siega-Riz AM, Popkin BM, Carson T. Trends in breakfast consumption for children in the United States from 19651991. J Am Clin Nutr 1998;67:748-56.

9. Sj6berg A, Hallberg L, H6glund D, Hulthén L. Meal pattern, food choice, nutrient intake and lifestyle factors in the G6teborg Adolescence Study. European J Clin Nutr 2003;57:1569-78.

10. Rampersaud GC, Pereira MA, Girard BL, Adams J, et al. Breakfast habits, nutritional status, body weight, and academic performance in children and adolescents. J Am Diet Assoc 2005;105(5):743-60.

11. Deshmukh-Taskar PR, Nicklas TA, O'Neil CE, Keast DR, et al. The Relationship of Breakfast Skipping and Type of Breakfast Consumption with Nutrient Intake and Weight Status in Children and Adolescents: The National Health and Nutrition Examination Survey 1999-2006. J Am Diet Assoc 2010;110:869-78.

12. Serra Majem L, Ribas Barba L, Aranceta Bartrina J, Pérez Rodrigo C, et al. Obesidad infantil y juvenil en España. Resultados del Estudio en Kid (1998-2000). Medicina Clínica 2003;121(19):725-32.

13. Angeleri MA, González I, Ghioldi MM, Petrelli L. Hábito de consumo del desayuno y calidad nutricional del mismo en niños y adolescentes de la zona norte del gran Buenos Aires: DIAETA 2007;25(116):7-13.

14. Reddan J, Wahlstrom K, Reicks M. Children's perceived benefits and barriers in relation to eating breakfast in schools with or without Universal School Breakfast. J Nutr Educ Behav 2002;34:47-52.

15. O'Sullivan TA, Robinson M, Kendall GE, Miller M, et al. A good-quality breakfast is associated with better mental health in adolescence. Public Health Nutr 2009;12(2):249-58.

16. Asociación Argentina de Dietistas y Nutricionistas Dietistas (AADyND). Guías Alimentarias para la Población Argentina. Consejos para una alimentación saludable. Argentina, 2000. [Acceso: 5 de septiembre de 2012]. Disponible en: http:/ / www.aadynd.org.ar/guias_ consejos.php.

17. Fernández Morales I, Aguilar Vilas M, C. J, Mateos Veja C y Martínez M. Relación entre la calidad del desayuno y el rendimiento académico en adolescentes de Guadalajara (Castilla-La Mancha). Nutr Hosp 2008;23(4):383-7.
18. Código Alimentario Argentino. Capítulo V: Normas para la rotulación y publicidad de los alimentos. Resolución GMC $n^{\circ}$ 47/ 03 - "Reglamento Técnico Mercosur de porciones de alimentos envasados a los fines del rotulado nutricional". Última actualización:2/2013. [Acceso: 20 de abril de 2013]. Disponible en: http://www.anmat.gov.ar/alimentos / codigoa/Capitulo_V.pdf].

19. Amat Huerta MA, Anuncibay Sánchez V, Soto Volante J, Alonso Nicolás J, et al. Estudio descriptivo sobre hábitos alimentarios en el desayuno y almuerzo de los preadolescentes de Viladecans (Barcelona). Nure Invest 2006;23: [Acceso: 2 de septiembre de 2013]. Disponible en http:www.fuden.es/ficherosadministrativos/original/ original_nute_23.pdf.

20. Utter J,Scragg R,Ni Murchu G, Schaaf D. At-homebreakfast consumption among New Zealand children: associations with body mass index and related nutrition behaviours. J Am Diet Assoc 2007;107:570-6.

21. Menal-Puey S, Fajó-Pascual M, Marques-Lopes I. Estudio descriptivo del desayuno en una población infantil inmigrante escolarizada, 2007-2010. Rev Esp Nutr Hum Diet 2011;15(4):177-83.

22. Affenito SG. Breakfast: a missed opportunity. J Am Diet Assoc 2007;107(4):565-9.

23. Pearson N, BiddleS, Gorely T. Family correlates of breakfast consumption among children and adolescents. Asystematic review. Appetite 2009;52:1-7.

24. Castells Cuixart M, Capdevila Prim C, Girbau Sola T, Rodríguez CabC. Estudio del comportamiento alimentario en escolares de 11 a 13 años de Barcelona. Nutr Hosp 2006;21(4):517-32.

25. Patrick HP, Nicklas TA. A Review of Family and Social Determinants of Children's Eating Patterns and Diet Quality. J Am College of Nutr 2005;24(2):83-92.

26. Ortega RM, Requejo AM, Redondo R, et al. Breakfasthabits of different groups of Spanish schoolchildren. J Hum Nutr Dietet 1996,9:33-41.

27. Ruxton CH,KirkTR. Breakfast: a review of associations with measures of dietary intake, physiology and biochemistry. British Journal of Nutrition 1997;78:199-213.

28. Fernández San Juan PM. Dietary habits and nutritional status of school aged children in Spain. Nutr Hosp 2006;21(3):374-8. 


\section{Annex 1}

School:

Name:

Weight:
Grade:

Age:

Height:

Sex:

1) Do you have breakfast?

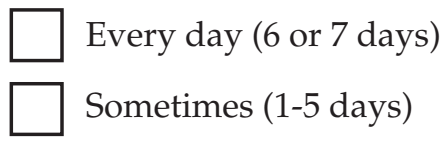

Never

2) Why don't you have breakfast every day?

$\square$ I don't have time
$\square$ It makes me feel unwell

I am not hungry

Other reason (specify)

3) Who makes your breakfast?

$$
\text { I make it myself }
$$

A family member

4) Who do you usually have breakfast with?
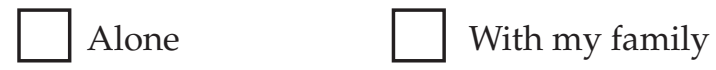

With other people (specify)

5) What do you do while having breakfast?

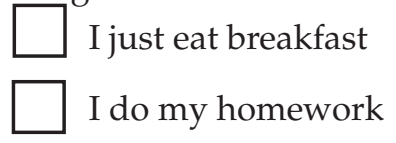

I do my homework

6) Before coming to school today, what did you eat and drink?

Provide a detailed list of all the food and drinks you had and their serving sizes

7) Are you going to eat or drink something during the morning?

Provide a detailed list of the food you had as a snack and their serving sizes 